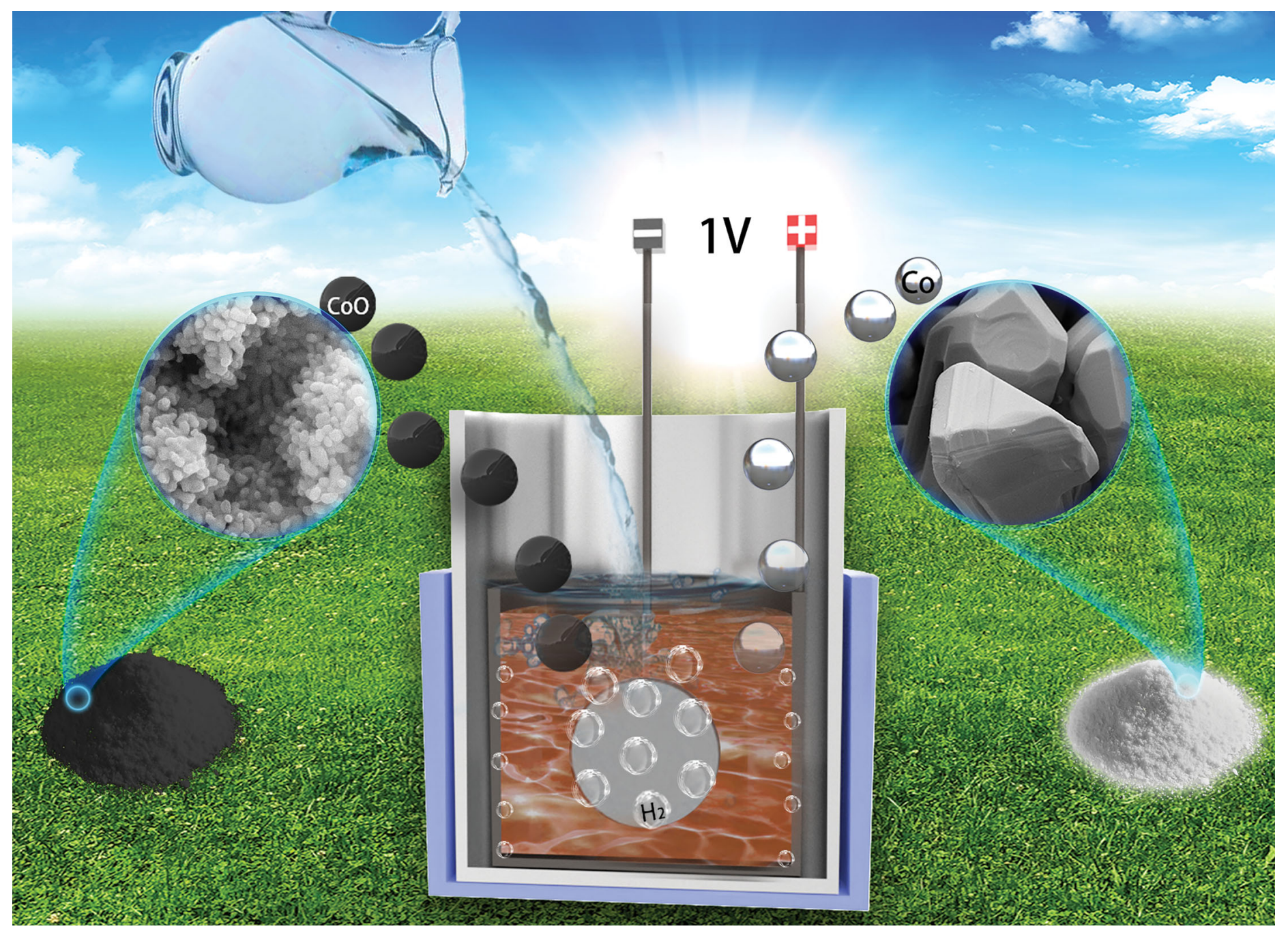

Showcasing research from Professor Ali Reza Kamali's laboratory, Energy and Environmental Materials Research Centre $\left(E^{2} M C\right)$, Northeastern University, China.

Green production of hydrogen-doped faceted cobalt microcrystals using water-assisted molten salt electro-reduction method

It is shown that water can repeatedly be decomposed and regenerated in molten $\mathrm{LiCl}$ at $680^{\circ} \mathrm{C}$ under a low cell voltage of only $1 \mathrm{~V}$, and these interactions lead to the clean production and the in situ consumption of hydrogen, and consequently, the electro-reduction of cobalt oxide into highly faceted cobalt microcrystals with dominant stable face-centered cubic phase with an energy consumption of $1150 \mathrm{~kW}$ h per ton of reduced cobalt. These features provide considerable advantages over the alternative approaches available for cobalt production.

\section{As featured in:}

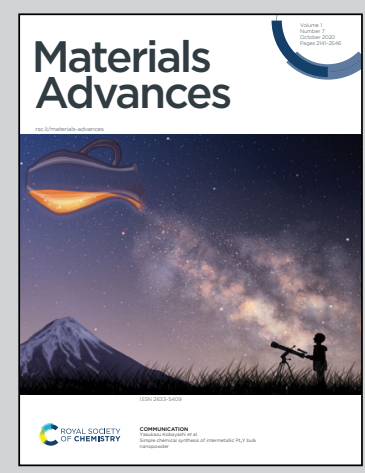

See Ali Reza Kamali et al., Mater. Adv., 2020, 1, 2225. 
Check for updates

Cite this: Mater. Adv., 2020, 1,2225

Received 9th June 2020,

Accepted 23rd August 2020

DOI: 10.1039/d0ma00399a

rsc.li/materials-advances

\title{
Green production of hydrogen-doped faceted cobalt microcrystals using water-assisted molten salt electro-reduction method $\dagger$
}

\author{
Dongwei Qiao, Kaiyu Xie (D) and Ali Reza Kamali (D)*
}

\begin{abstract}
We report that water can repeatedly be decomposed and regenerated in molten $\mathrm{LiCl}$ at $680{ }^{\circ} \mathrm{C}$ under a low cell voltage of only $1 \mathrm{~V}$, and these interactions lead to the clean production and in situ consumption of hydrogen, and, consequently, to the electro-reduction of cobalt oxide to highly faceted cobalt microcrystals with a dominant stable face-centered cubic (fcc) phase with an energy consumption of $1150 \mathrm{~kW}$ h per ton of reduced cobalt, providing considerable advantages over the alternative approaches available for cobalt production. The phase and morphological evolution that occurred is shown to follow the sequence: $\mathrm{CoO} \rightarrow \mathrm{CO}_{3} \mathrm{O}_{4} \rightarrow \mathrm{Li}_{0.065} \mathrm{CO}_{0.935} \mathrm{O} \rightarrow \mathrm{Co}$. The establishment of the desirable high temperature $\mathrm{fcc}-\mathrm{Co}$ phase at room temperature, observed in this study, is related to the doping of $\mathrm{Co}$ crystals with hydrogen. The mechanism involved in the water-assisted clean electro-reduction of cobalt oxide is systematically investigated.
\end{abstract}

\section{Introduction}

Cobalt, which is a transition metal with a current world production of around 140 million metric tons per annum, has a wide range of applications in several fields. It is a common ferromagnetic metal with the highest Curie point, and therefore is widely used to fabricate magnetic alloys. ${ }^{1}$ It is also employed in the fabrication of corrosion and wear-resistant alloys, ${ }^{2}$ catalysts, ${ }^{3,4}$ hard compounds ${ }^{5,6}$ and rechargeable batteries. ${ }^{7,8}$ Moreover, Co powder is particularly interesting for the preparation of advanced materials such as soft magnets, ${ }^{9,10}$ additive manufactured alloys and cemented carbides. ${ }^{11}$

The stable crystalline form of cobalt is a hexagonal close packed (hcp) structure up to about $420{ }^{\circ} \mathrm{C}$, above which the face-centred cubic (fcc) structure becomes stable. ${ }^{12}$ The establishment of an fcc-Co structure at room temperature is highly beneficial for applications such as industrially important hard materials, in which cobalt is surrounded by hard carbides. ${ }^{13-15}$ Moreover, the clean and low cost production of cobalt is challenging. This article concerns the green production of Co powder with a dominant stable fcc phase, as further explained below.

Cobalt powder can be produced by the direct hydrogen reduction of cobalt oxalate, carbonate or oxides in the temperature range of 400 to $800{ }^{\circ} \mathrm{C} .{ }^{11,16-18}$ The hydrogen reduction process

Energy and Environmental Materials Research Centre ( $\left.E^{2} M C\right)$, School of Metallurgy, Northeastern University, Shenyang 110819, China.E-mail: ali@smm.neu.edu.cn, a.r.kamali@cantab.net

$\dagger$ Electronic supplementary information (ESI) available. See DOI: 10.1039/d0ma00399a proceeds through the conversion of $\mathrm{Co}_{3} \mathrm{O}_{4}$ to $\mathrm{CoO}$ and then to metallic Co. ${ }^{19}$ Although hydrogen reduction is considered as a clean method, hydrogen gas should first be produced, mainly from non-renewable fossil fuels, and then the hydrogen product needs to be stored and transported to the reduction reactor. Therefore, the production, storage, and transportation of hydrogen gas are key challenges in these methodologies. ${ }^{20,21}$ Other reducing agents such as ethanol $\left(\mathrm{C}_{2} \mathrm{H}_{5} \mathrm{OH}\right)^{18}$ have also been utilised to reduce cobalt oxides in the temperature range of $800-950{ }^{\circ} \mathrm{C}$. Although the liquid ethanol is easier to transport than hydrogen gas, its highly toxic nature $\mathrm{e}^{22}$ and production cost present additional challenges.

Alternatively, cobalt can be extracted using electrochemical methods, avoiding the problems associated with chemical reducing agents. These methods can mainly be divided into two categories. The methods in the first category are based on the electrodeposition of cobalt from aqueous solutions such as acidic $\mathrm{CoSO}_{4} \cdot 7 \mathrm{H}_{2} \mathrm{O}-\mathrm{Na}_{2} \mathrm{SO}_{4}$ in the presence of tetraethylammonium bromide ${ }^{23}$ or non-aqueous low-temperature electrolytes containing electroactive soluble Co species such as $\mathrm{CoCl}_{2}$ in urea acetamide- $\mathrm{LiBr}^{24}$ or $\mathrm{Co}(\mathrm{TFSA})_{2}$ in 1-butyl-1-methylpyrrolidinium bis(trifluoromethylsulfonyl)amide in the presence of coumarin and thiourea. ${ }^{25}$ Unfortunately, the application of these lowtemperature electrolytic methods is restricted due to the expensive and environmentally problematic reagents involved, and also the low kinetics of the processes conducted at low temperatures, as well as the low quality of the deposited cobalt. In the presence of water, the parasitic hydrogen evolution reaction taking place during the process can also impose additional limitations, thus reducing the current efficiency of the process. It should be 
noticed that hydrogen cannot reduce cobalt oxide at low temperatures due to kinetic barriers.

The second approach used for the electrochemical extraction of cobalt is based on the direct cathodic electrodeoxidation of solid cobalt oxides in high temperature molten salt electrolytes, ${ }^{26-29}$ such as $\mathrm{Na}_{2} \mathrm{CO}_{3}-\mathrm{K}_{2} \mathrm{CO}_{3}\left(800{ }^{\circ} \mathrm{C}\right.$, cell voltage $>1.7 \mathrm{~V}, 5 \mathrm{~h}) .{ }^{26}$ It should be noted that the working current densities achieved using high-temperature molten salts can be considerably greater than those obtained using lowtemperature electrolytes, avoiding the sluggish kinetics and unacceptable production yield. Despite this advantage, the high temperature and cell voltage required in these molten salt methods increase the processing cost. Side reactions can also be promoted at high cell voltages/temperatures, which further reduce the quality of the product and the efficiency of the process. Therefore, the development of a new generation of molten salt technologies that can work at lower temperatures and cell potentials will be of great interest.

On the other hand, all the methods mentioned above lead to the preparation of cobalt with a dominant hcp structure, which is not the preferred crystalline structure for some important applications. For instance, cobalt is extensively used in the fabrication of WC/Co composites for applications such as cutting and forming tools, pressing dies, mining bits and wear resistant components ${ }^{29}$ due to their outstanding thermal, chemical and mechanical properties, brought about by the presence of a hard and brittle WC phase dispersed in a soft Co binder matrix. The latter is responsible for improving the ductility and toughness of the composite. ${ }^{30}$

It should be mentioned that fcc-Co exhibits a higher value of toughness in comparison with hcp-Co since more slip systems are activated in the former. Therefore, the presence of Co binder in its fcc structure at room temperature can enhance the toughness of cemented carbides, which is critically important. $^{31-33}$ Consequently, the stabilisation of the fcc-Co phase at room temperature is a highly demanding topic from both scientific and practical points of view. It is reported that the high energy ball milling of cobalt powder consisting of $78 \%$ hcp phase and $22 \%$ fcc phase for $15 \mathrm{~h}$ can lead to an increase in the amount of the fcc phase to around $38 \% .^{34,35}$ It is also known that elements such as tungsten and carbon stabilise the fcc-Co at room temperature. As a result, the nanostructuring of WC-Co was found to be effective to increase the dissolution of tungsten and carbon in the Co binder, leading to the presence of a higher fcc-Co/hcp-Co ratio at room temperature, thus improving the mechanical properties of the composite material. ${ }^{36,37}$ The ratio of fcc-Co/hcp-Co and therefore the toughness of the resultant cemented carbides can also be increased by doping of the Co phase with elements such as $\mathrm{Y}$, Ce, La, Pr, Nd, Gd, Sm and Fe. ${ }^{38,39}$

To conclude, despite the commercial and scientific importance of cobalt, its extraction is challenging in terms of energy consumption and environmental impacts. Furthermore, the current technologies of reducing cobalt oxides produce hcp-Co, which is less desirable than fcc-Co for practical applications. Here, for the first time, a simple molten salt method is proposed for the green production of Co with a dominant stable fcc structure.

Recently, we have demonstrated a water-assisted molten salt method for the facile generation of hydrogen in molten LiCl. In this approach, water as a clean source of hydrogen is fed into the molten salt reactor and this consequently leads to the formation of hydrogen cations and oxygen anions in the melt through the hydrolysis reaction. ${ }^{40}$ In this way, hydrogen can be generated on cathodically polarised electrodes and utilised for various interesting applications including the efficient exfoliation of graphite to fabricate high-quality graphene, ${ }^{4-44}$ carbon encapsulated silicon ${ }^{45}$ and a diamond precursor. ${ }^{46}$ The generated hydrogen can also be utilized for the reduction of iron oxides. ${ }^{47,48}$ Since hydrogen is generally regarded as a clean reducing agent, this molten salt technology can be considered as a sustainable and economical alternative for the state-of-theart electrochemical production of metallic iron. It is important to consider that hydrogen production in molten salts requires a low cell potential of less than $1 \mathrm{~V}$ at temperatures less than $700{ }^{\circ} \mathrm{C}$, which makes the process attractive for the large scale production of metals from their oxides.

In this paper, we investigated the electro-extraction of cobalt from a cobalt oxide precursor by the in situ generated hydrogen in molten LiCl. The process parameters including the production yield, current efficiency, and energy consumption involved in the production of metallic cobalt, as well as the mechanisms involved in the process, are discussed. Interestingly, we show that water, as the source of hydrogen, can be continuously consumed and regenerated during the process. The Co product displays a distinguished crystalline faceted morphology with a dominant fcc structure, which is formed due to hydrogen doping. The presented results are interesting, suggesting a green method for the facile synthesis of faceted cobalt crystals, which cannot be produced by alternative methods.

\section{Experimental procedure}

\subsection{Materials and methods}

Anhydrous lithium chloride (Sigma-Aldrich, V900067) and cobalt oxide (CoO, Aladdin, C104343) were used as the molten salt electrolyte and the cobalt precursor, respectively. The mixtures of $\mathrm{CoO}$ powder and 20 wt $\% \mathrm{NH}_{4} \mathrm{HCO}_{3}$ (Aladdin, A110536) were pressed into cylindrical pellets with a diameter of $20 \mathrm{~mm}$ at a uniaxial pressure of $20 \mathrm{MPa}$. The pellets were then sintered at $1300{ }^{\circ} \mathrm{C}$ for $2 \mathrm{~h}$ so as to achieve the desired strength. Thereafter, the sintered pellets were connected to one end of copper rods sheathed with alumina tubes. These assemblies were used as the working cathode during the molten salt experiments. Meanwhile, a graphite crucible (internal diameter: $55 \mathrm{~mm}$ and height: $150 \mathrm{~mm}$ ) containing $250 \mathrm{~g}$ of $\mathrm{LiCl}$ powder was used as the salt container and the anode during the electrolysis process. The assembled cell was placed inside a gas sealed Inconel retort, located in a vertical resistance furnace equipped with SiC heating elements. Then, the furnace was heated to $680{ }^{\circ} \mathrm{C}$ at a ramping rate of $3{ }^{\circ} \mathrm{C} \mathrm{min}{ }^{-1}$ under a dry 


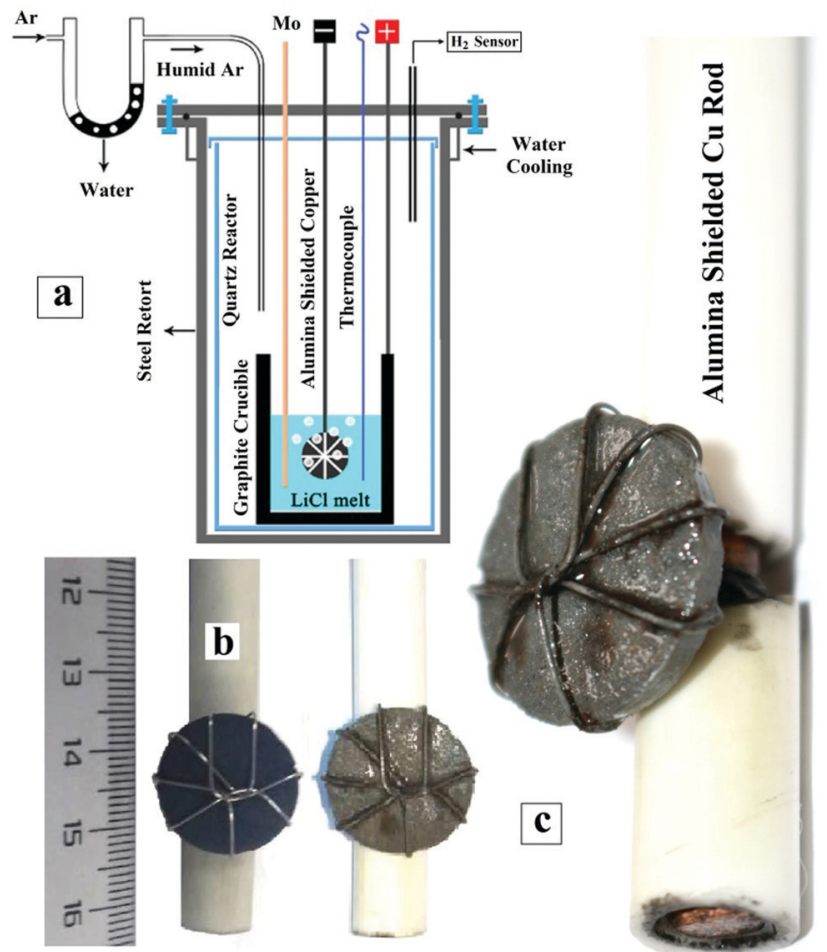

Fig. 1 (a) Experimental setup used for hydrogen production and the reduction of cobalt oxide in molten $\mathrm{LiCl}$. (b) Photograph of the sintered $\mathrm{CO}_{3} \mathrm{O}_{4}$ pellet before the molten salt process. (c) Photographs of reduced metallic $\mathrm{Co}$ after the hydrogen reduction process.

argon flow. The cell was maintained for 30 minutes at the target temperature, and then the dry argon was replaced by a humid argon flow brought about by allowing the argon to flow through a quartz tube containing deionized water. The humid argon was purged in the system for 10 minutes before the electrodes were connected to the terminals of a computer-controlled DC power supply (IT6502D, ITECH). The electrolysis experiments were conducted at a low voltage of $1 \mathrm{~V}$ for different durations up to $8 \mathrm{~h}$, during which the cathodic and anodic potential differences versus the molybdenum quasi-reference electrode (QRE) were recorded using two digital multimeters (Keysight, 34460A). Fig. 1a exhibits the experimental setup. At the end of the electrolysis, the cell was cooled down to room temperature at a rate of $3{ }^{\circ} \mathrm{C} \mathrm{min}^{-1}$ under a dry argon atmosphere. Then, the materials inside the crucible were washed with distilled water to retrieve the reduced pellets, which were subsequently freeze-dried before further characterisation.

\subsection{Materials characterisation}

The electrolytic products obtained from the experiments were characterised using X-ray diffraction $\left(\mathrm{XRD}, \mathrm{Cu}-\mathrm{K}_{\alpha}\right.$ radiation $\lambda=1.5405 \AA$, PANalytical) and scanning electron microscopy (SEM, Ultra Plus - ZEISS) equipped with an energy dispersive spectrometer (EDX, Shimadzu). The oxygen, carbon and hydrogen contents of the electrolytic product were characterised using a CHNO analyzer (PerkinElmer). The relative amounts of the fcc and hep phases in the Co product were quantified via
Rietveld refinement of the corresponding XRD patterns using X-Pert HighScore Plus software.

\section{Results and discussion}

\subsection{Phase evolution of cobalt oxide caused by the electroless molten salt treatment}

The phase evolution of the Co oxide precursor that occurred by heating of the material in molten LiCl under a dry or humid Ar atmosphere was studied by means of XRD, and the results are shown in Fig. 2. Fig. 2a shows the XRD analysis of the precursor, indicating that the material is pure $\mathrm{CoO}$ with no traceable impurity. This material was mixed with $\mathrm{LiCl}$ and the mixture was loaded into a graphite crucible and heated under a dry argon flow at $680{ }^{\circ} \mathrm{C}$ for $1 \mathrm{~h}$ in the gas-tight Inconel reactor. After the heating process, the crucible content was washed and vacuum-filtered, and the filtrate was vacuum-dried for $2 \mathrm{~h}$. Fig. $2 \mathrm{~b}$ shows the XRD analysis of the material obtained, providing the evidence that $\mathrm{CoO}$ is partially converted to $\mathrm{Co}_{3} \mathrm{O}_{4}$ during the heat treatment process:

$$
6 \mathrm{CoO}+\mathrm{O}_{2}(\mathrm{~g})=2 \mathrm{Co}_{3} \mathrm{O}_{4} \quad \Delta G^{\circ}=-96 \mathrm{~kJ}\left(680{ }^{\circ} \mathrm{C}\right)
$$

Such an oxidation process was also indicated in the work of Zyłaa. ${ }^{49}$ The oxygen required for the occurrence of reaction (1) was likely to be sourced from the remaining oxygen trapped in the system.

The aforementioned experiment was repeated with the only difference being that the high temperature heat treatment at $680{ }^{\circ} \mathrm{C}(1 \mathrm{~h})$ was conducted under a humid $\mathrm{Ar}$ gas flow. The X-ray diffraction pattern of the product, shown in Fig. 2c, demonstrates the formation of a new phase described as $\mathrm{Li}_{0.065} \mathrm{Co}_{0.935} \mathrm{O}$. This phase transformation can be explained based on the reaction between molten $\mathrm{LiCl}$, water from the moist atmosphere and the oxygen remaining in the system:

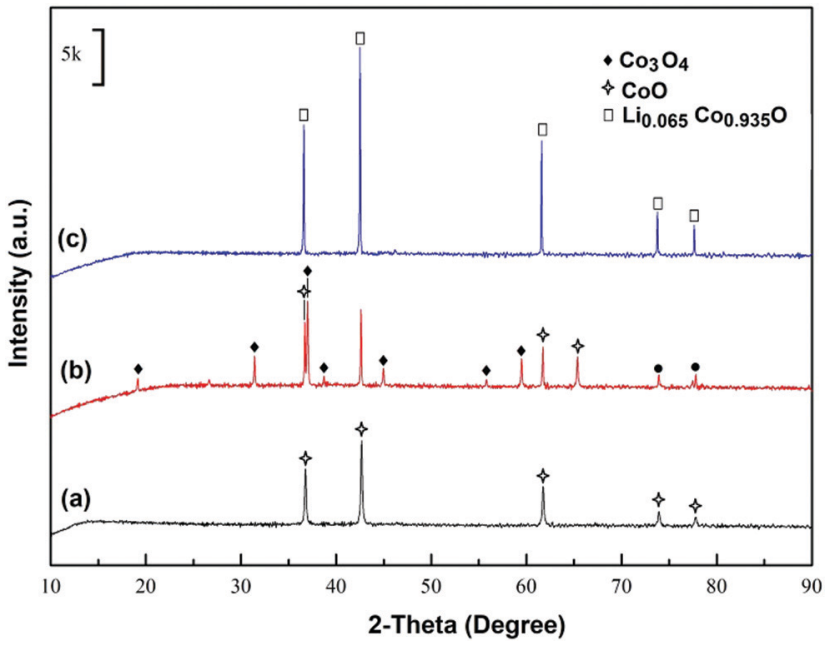

Fig. 2 XRD analysis of (a) the cobalt oxide powder used as the precursor material and the material obtained by heating the powder precursor with $\mathrm{LiCl}$ (b) under dry $\mathrm{Ar}$ and (c) under humid $\mathrm{Ar}$ at $680^{\circ} \mathrm{C}$ for $2 \mathrm{~h}$. 


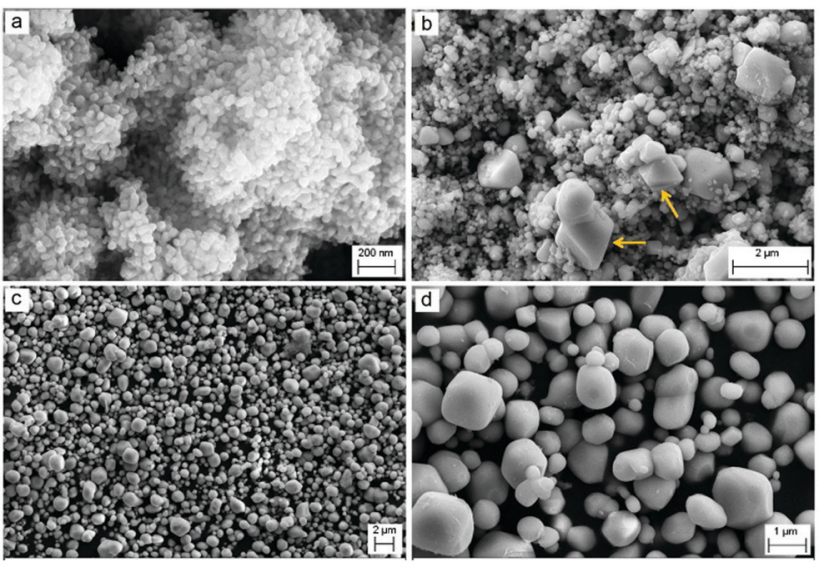

Fig. 3 SEM micrographs of (a) the Co oxide powder used as the precursor material and the material obtained by heating the powder precursor with $\mathrm{LiCl}$ (b) under dry $\mathrm{Ar}$ and (c and d) under humid $\mathrm{Ar}$ at $680^{\circ} \mathrm{C}$ for $2 \mathrm{~h}$. Arrows in (b) point at $\mathrm{CO}_{3} \mathrm{O}_{4}$ octahedral crystals.

$$
\begin{aligned}
0.13 \mathrm{LiCl} & +0.065 \mathrm{H}_{2} \mathrm{O}+1.87 \mathrm{CoO}+0.0325 \mathrm{O}_{2} \\
& =2 \mathrm{Li}_{0.065} \mathrm{Co}_{0.935} \mathrm{O}+0.13 \mathrm{HCl}
\end{aligned}
$$

The phase evolutions discussed above caused major morphological changes. As depicted in Fig. 3a, the raw CoO powder comprised agglomerated rather uniform spherical particles with a size of around $50 \mathrm{~nm}$. According to the SEM micrographs shown in Fig. 4b-d, the particle sizes of the cobalt oxide powder increase during the heat treatment processes performed under different conditions. After heating in molten salt under the dry atmosphere, the product does not exhibit a uniform morphology anymore. Instead, it includes particles with a wide size distribution from around $100 \mathrm{~nm}$ to more than $1 \mu \mathrm{m}$. The larger particles are likely to be $\mathrm{Co}_{3} \mathrm{O}_{4}$, considering the results of the $\mathrm{XRD}$ analysis shown in Fig. 2b. As pointed out by arrows in Fig. 3b, some particles have grown further into highly faceted octahedral crystals with a size greater than $1 \mu \mathrm{m}$. These crystals can be attributed to $\mathrm{Co}_{3} \mathrm{O}_{4}$ with a cubic structure (JCPDS: 010761802) formed through the occurrence of reaction (1). On the other hand, the molten salt heating of the raw $\mathrm{CoO}$ powder under humid Ar led to the formation of approximately uniform particles with an average size of around $1 \mu \mathrm{m}$ (Fig. 3c and $\mathrm{d}$ ). These particles correspond to $\mathrm{Li}_{0.065} \mathrm{Co}_{0.935} \mathrm{O}$ according to the XRD pattern shown in Fig. 2c. We emphasize that these structural and morphological changes occurred solely due to the molten salt heat treatment of the raw CoO powder with no polarisation contribution.

\subsection{Phase evolution of cobalt oxide caused by molten salt electrolysis}

Before the electrolysis process, $\mathrm{CoO}$ powders were pressed into pellets and then sintered in air at $1300{ }^{\circ} \mathrm{C}$ to achieve sufficient mechanical properties. The XRD pattern of the sintered pellets is presented in Fig. 4a. The pattern confirms the completion of reaction (1) that occurred at high temperatures in air, leading to the formation of $\mathrm{Co}_{3} \mathrm{O}_{4}$.

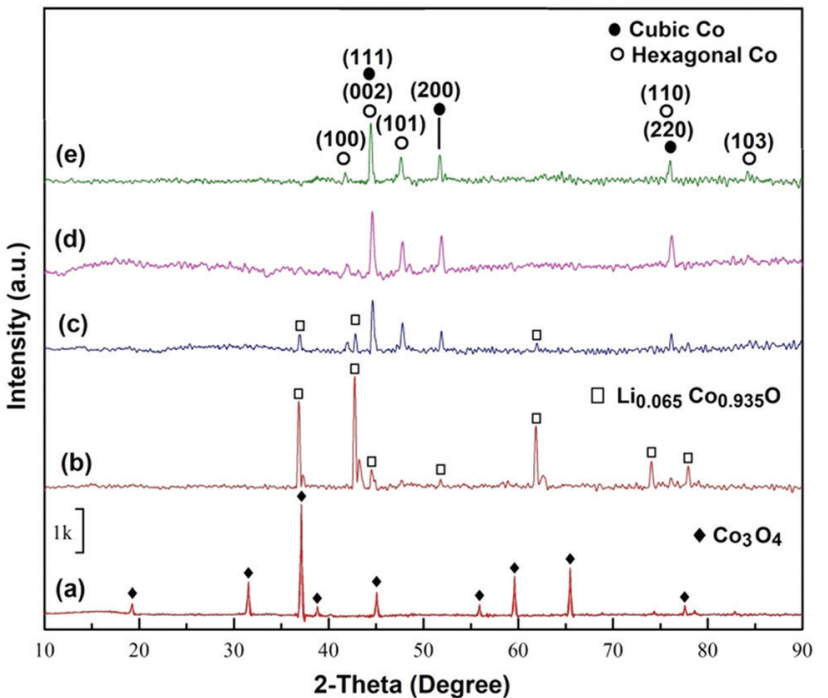

Fig. 4 X-ray diffraction patterns of (a) Co oxide after being pressed and sintered at $1300{ }^{\circ} \mathrm{C}$ and the electrolytic products obtained after various electrolysis durations under humid Ar at a low cell potential of $1 \mathrm{~V}$ : (b) $2 \mathrm{~h}$, (c) $4 \mathrm{~h}$, (d) $6 \mathrm{~h}$ and (e) $8 \mathrm{~h}$.

Fig. $1 \mathrm{~b}$ and $5 \mathrm{a}$ show the photograph and the SEM morphology of the sintered pellet, respectively. It is evident that during the sintering process, spherical $\mathrm{CoO}$ nanoparticles (Fig. 3a) transformed into $\mathrm{Co}_{3} \mathrm{O}_{4}$ with a knitt morphology comprising semi-spherical particles with a size of around $2 \mu \mathrm{m}$ and sinter neck features.

The $\mathrm{Co}_{3} \mathrm{O}_{4}$ pellets were cathodically polarized in molten $\mathrm{LiCl}$ under humid Ar at a low cell voltage of $1 \mathrm{~V}$ for $2 \mathrm{~h}$, and the XRD analysis of the electrolytic product is shown in Fig. $4 \mathrm{~b}$, indicating that the product consisted of the $\mathrm{Li}_{0.065} \mathrm{Co}_{0.935} \mathrm{O}$ phase. By comparing Fig. 4b and Fig. 2c, it can be concluded that $\mathrm{Li}_{0.065} \mathrm{Co}_{0.935} \mathrm{O}$ was formed via chemical reaction (2), which occurred under the influence of the humid atmosphere, before the initiation of polarisation. It also confirms that $2 \mathrm{~h}$ of cathodic polarisation of $\mathrm{Li}_{0.065} \mathrm{Co}_{0.935} \mathrm{O}$ at $1 \mathrm{~V}$ does not lead to a major phase evolution. The morphology of this sample is, however, different from that shown in Fig. 4b. The powder obtained included large particles of around $10 \mu \mathrm{m}$ size together with smaller ones, as depicted in Fig. 5b. We believe that large particles are mainly formed on the surface of the pellet, where the sintered powders were fully exposed to the molten salt, providing a high-temperature ionic medium to facilitate the diffusion, and hence the sintering of smaller particles into larger ones. Fig. 5c and Fig. S1 (ESI $\dagger$ ) show the SEM micrographs taken from the surface of some large particles. The micrograph exhibits the presence of nanosheet-like entities on the surface of the particle, representing the feature of exfoliation. This may be an indication of the formation of hydrogen and surface reduction of the particle.

After $4 \mathrm{~h}$ of electrolysis, a substantial structural change was recorded, as can be seen from the XRD pattern shown in Fig. 4c. In this pattern, the intensities of diffraction peaks related to $\mathrm{Li}_{0.065} \mathrm{Co}_{0.935} \mathrm{O}$ have been significantly reduced, and those of cobalt appeared. The Co phase displays a predominantly cubic 

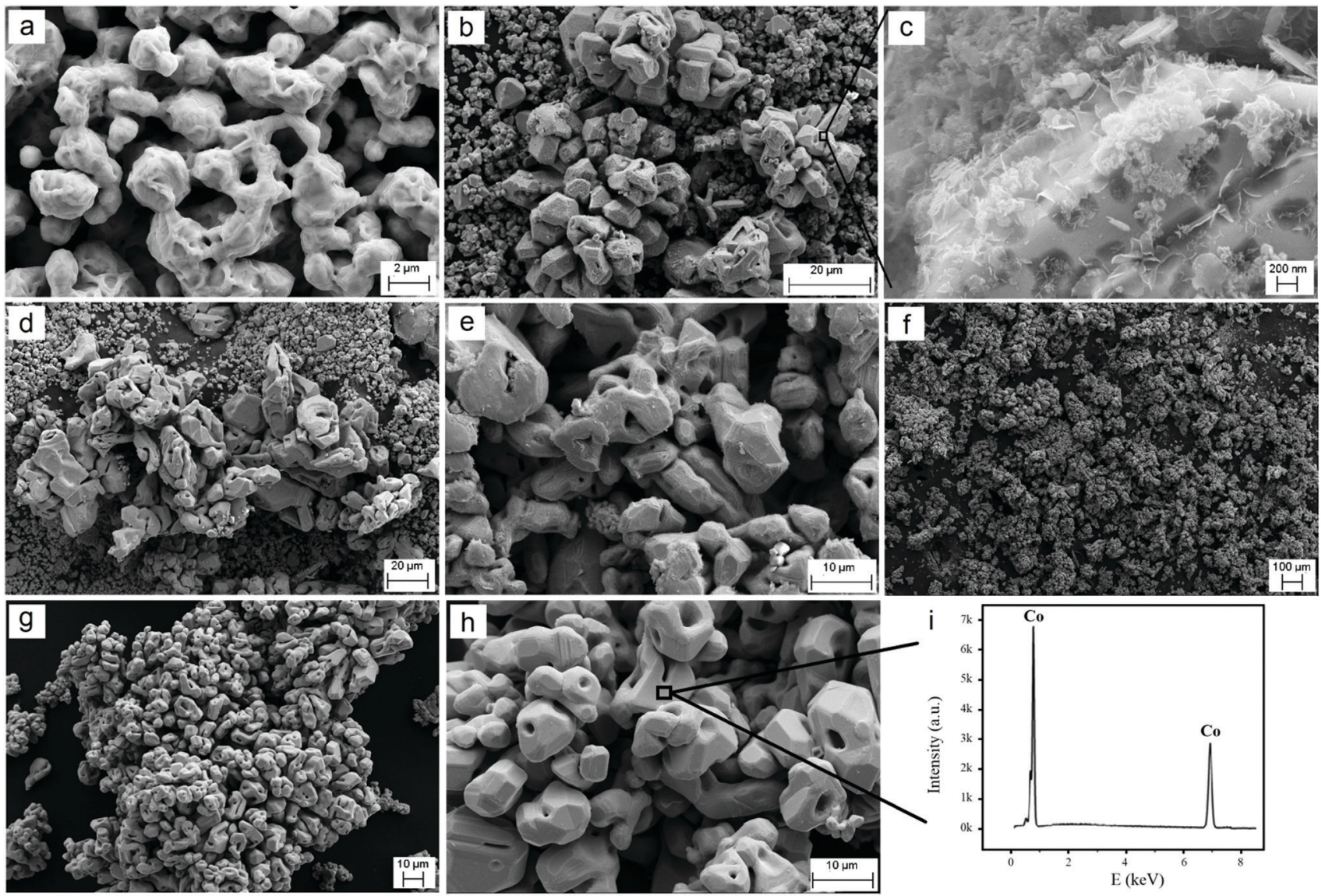

Fig. 5 SEM micrographs of (a) $\mathrm{Co}_{3} \mathrm{O}_{4}$ pellets sintered at $1300^{\circ} \mathrm{C}$; ( $\mathrm{b}$ and $\mathrm{c}$ ) the electrolytic product obtained through the cathodic polarisation of the pellets at $680{ }^{\circ} \mathrm{C}$ under the humid Ar atmosphere at a cell voltage of $1 \mathrm{~V}$ for (b and c) $2 \mathrm{~h}$, (d) $4 \mathrm{~h}$, (e and f) $6 \mathrm{~h}$, and (g and h) $8 \mathrm{~h}$. (i) EDX elemental analysis recorded on the area identified in the SEM micrograph of (h)

structure with a smaller fraction of hep structure. The morphology of the sample, shown in Fig. 5d, is similar to that obtained after $2 \mathrm{~h}$ of electrolysis, consisting of larger particles of around $10 \mu \mathrm{m}$ size and much smaller ones.

After $6 \mathrm{~h}$ of electrolysis, the X-ray diffraction peaks of $\mathrm{Li}_{0.065} \mathrm{Co}_{0.935} \mathrm{O}$ completely vanished, so that those related to metallic cobalt could only be detected in the pattern shown in Fig. $4 d$. The $\operatorname{Co}(2 p)$ XP spectrum of the sample (Fig. S2, ESI $\dagger$ ) shows two sharp peaks related to $\mathrm{Co}^{0}\left(2 \mathrm{p}_{3 / 2}\right)$ at $781.2 \mathrm{eV}$ and $\left(2 \mathrm{p}_{1 / 2}\right)$ at $796.9 \mathrm{eV}$, as well as two considerably weaker peaks related to $\mathrm{Co}^{2+, 3+}\left(2 \mathrm{p}_{3 / 2}\right)$ at $786.7 \mathrm{eV}$ and $\left(2 \mathrm{p}_{1 / 2}\right)$ at $803.2 \mathrm{eV}$. These results exhibit the dominant presence of metallic cobalt on the surface, ${ }^{50}$ while a minor quantity of surface oxides can also be expected. ${ }^{51}$

The SEM micrograph of the sample, shown in Fig. 5e, demonstrates that Co particles are in the form of irregularly shaped crystals, mostly 5-10 $\mu \mathrm{m}$ in size. The lower magnification image shown in Fig. $5 \mathrm{f}$ indicates that the crystalline particles are rather uniform, confirming the completion of the phase transitions explained above.

After a longer electrolysis period of $8 \mathrm{~h}$, metallic cobalt crystals formed with a mixed crystalline structure of fcc and hcp could still be identified in the XRD pattern of Fig. 4e. Cobalt crystals had a uniform size of around $5-10 \mu \mathrm{m}$, as observed from the SEM micrographs shown in Fig. $5 \mathrm{~g}$ and $\mathrm{h}$. The EDX analysis recorded on a crystal in Fig. $5 \mathrm{~h}$ is shown in Fig. 5i, demonstrating the formation of pure metallic cobalt. Further evidence for the formation of metallic cobalt could be obtained from the photograph of the reduced pellet after $6 \mathrm{~h}$ of electrolysis, as shown in Fig. 1c. The silver-gray appearance of the pellet, in comparison with the black color of the sintered pellet (Fig. 1b), is evident.

The results indicate that $\mathrm{Co}_{3} \mathrm{O}_{4}$ particles have been reduced to well-faceted cobalt microcrystals. Such large size Co crystals have not been reported in the literature previously, to the best of our knowledge. The mechanism involved in the formation of the Co crystals is discussed briefly in this article.

\subsection{Electro-reduction of $\mathrm{Co}_{3} \mathrm{O}_{4}$ pellets in the presence of water as the redox agent}

From the XRD patterns shown in Fig. 2, 3 and Fig. S3 (ESI $\dagger$ ), we can assume that before the start of electrolysis at $680{ }^{\circ} \mathrm{C}$, the pellet had a phase composition of mainly $\mathrm{Li}_{0.065} \mathrm{Co}_{0.935} \mathrm{O}$ with a fraction of $\mathrm{Co}_{3} \mathrm{O}_{4}$. The reduction of this material in molten $\mathrm{LiCl}$ in the presence of moist $\mathrm{Ar}$ can be explained based on the chemical and electrochemical events occurring during the process. As mentioned in the Experimental section, before the initiation of the electrolysis process, the lithium chloride 
was completely melted and maintained at $680{ }^{\circ} \mathrm{C}$ for $30 \mathrm{~min}$, during the last $10 \mathrm{~min}$ of which the humid argon gas was injected at a rate of $600 \mathrm{~cm}^{3} \mathrm{~min}^{-1}$ into the system. Under this condition, the reaction occurring between molten $\mathrm{LiCl}$ and the incoming water vapor could lead to the formation of $\mathrm{HCl}$ and $\mathrm{Li}_{2} \mathrm{O}$, which are both soluble in the molten salt. This leads to the generation of soluble $\left[\mathrm{H}^{+}\right]$and $\left[\mathrm{O}^{2-}\right]$ species in the melt: ${ }^{40-47}$

$$
2 \mathrm{LiCl}(\text { melt })+\mathrm{H}_{2} \mathrm{O} \text { (atmosphere) }=2[\mathrm{HCl}]_{\mathrm{LiCl}}+\left[\mathrm{Li}_{2} \mathrm{O}\right]_{\mathrm{LiCl}}
$$

$$
\begin{aligned}
& {[\mathrm{HCl}]_{\mathrm{LiCl}}=2\left[\mathrm{H}^{+}\right]_{\mathrm{LiCl}}+\left[\mathrm{Cl}^{-}\right]_{\mathrm{LiCl}}} \\
& {\left[\mathrm{Li}_{2} \mathrm{O}\right]_{\mathrm{LiCl}}=\left[\mathrm{Li}^{+}\right]_{\mathrm{LiCl}}+\left[\mathrm{O}^{2-}\right]_{\mathrm{LiCl}}}
\end{aligned}
$$

The Ni wires, wrapped around the cobalt oxide, are conductive. Therefore, under the influence of a cell voltage of $1 \mathrm{~V}$, $\mathrm{H}^{+}$and $\mathrm{O}^{2-}$ arising from the interaction of water in the melt (reactions (4.1) and (4.2), respectively) can be discharged on the cathodically polarised conductive $\mathrm{Ni}$ wires and the graphite crucible anode to produce cathodic hydrogen and anodic oxygen.

$$
\begin{gathered}
2\left[\mathrm{H}^{+}\right]_{\mathrm{LiCl}}+2 \mathrm{e}=\mathrm{H}_{2}(\mathrm{~g}) \quad \text { On the cathode } \\
{\left[\mathrm{O}^{2-}\right]_{\mathrm{LiCl}}=0.5 \mathrm{O}_{2}+2 \mathrm{e} \quad \text { On the anode }}
\end{gathered}
$$

The hydrogen gas produced on the cathode can either escape from the melt to the atmosphere (reaction (6)) or alternatively react with the pellet to produce cobalt (reactions (6.1) and (6.2)).

$$
\mathrm{H}_{2} \text { (melt) } \rightarrow \mathrm{H}_{2} \text { (atmosphere) }
$$

Or

$$
\begin{gathered}
4 \mathrm{H}_{2}+\mathrm{Co}_{3} \mathrm{O}_{4} \text { (pellet) }=3 \mathrm{Co}+4\left[\mathrm{H}_{2} \mathrm{O}\right]_{\mathrm{LiCl}} \\
\Delta G^{\circ}=-236.3 \mathrm{~kJ} \text { at } 670{ }^{\circ} \mathrm{C} \\
0.9675 \mathrm{H}_{2}+\mathrm{Li}_{0.065} \mathrm{Co}_{0.935} \mathrm{O} \text { (pellet) }=0.935 \mathrm{Co} \\
+0.0325\left[\mathrm{Li}_{2} \mathrm{O}\right]_{\mathrm{LiCl}}+0.9675\left[\mathrm{H}_{2} \mathrm{O}\right]_{\mathrm{LiCl}}
\end{gathered}
$$

\subsection{Mechanism involved in the hydrogen electro-reduction} process

In an electrolytic cell, the reactions occurring on the electrodes polarised under a cell voltage lead to the generation of an electric current. Therefore, the plots of current-time and voltage-time can provide valuable information to understand the mechanism involved in the electrochemical process, which in our case is the electro-reduction of $\mathrm{Co}_{3} \mathrm{O}_{4}\left(\mathrm{Li}_{0.065} \mathrm{Co}_{0.935} \mathrm{O}\right)$ to metallic cobalt. Fig. 6 shows the current-time curve recorded upon the cathodic polarisation of the $\mathrm{Ni}$ wrapped $\mathrm{Co}_{3} \mathrm{O}_{4}$ $\left(\mathrm{Li}_{0.065} \mathrm{Co}_{0.935} \mathrm{O}\right)$ cathode versus the graphite crucible anode conducted under the humid Ar atmosphere at a low cell potential of $1 \mathrm{~V}$.

3.4.1. Current-time variations. The $I-t$ curve recorded can be divided into four sections, suggesting four distinct steps throughout the entire electrolytic process, as indicated in Fig. 6. At the beginning of the electrolysis, the current decreased from a high value of 1.14 A to a value of 0.14 A during the initial

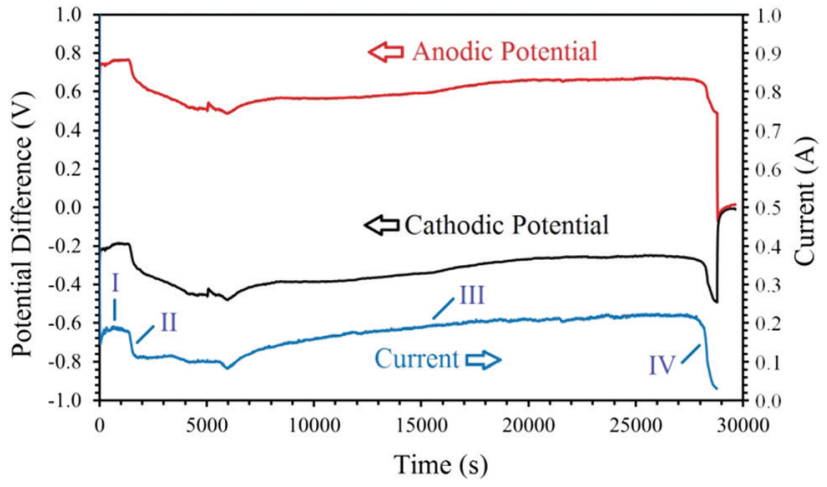

Fig. 6 Changes of the cell current versus the electrolysis time achieved by conducting the electrolysis at $1 \mathrm{~V}$. Potential differences between the cathode/anode and the Mo QRE are also shown.

42 seconds after the initiation of polarisation. This section cannot be clearly recognised in Fig. 6 due to the small time scale. The initial current drop is mainly attributed to capacitive current decay. Then, the current is slightly increased to about $0.19 \mathrm{~A}$, which can be due to the reduction of hydrogen cations from the melt on the conductive $\mathrm{Ni}$ wires (reaction (5.1)), producing hydrogen gas. This represents stage I in Fig. 6. Thereafter, the current decreases to values in the range of 0.11-0.08 A and remains at the same level for approximately 99 min (stage II). The observed current reduction can be related to the gradual passivation of the $\mathrm{Ni}$ wires, increasing the surface resistance. The third step in the electrochemical process is characterised by a gradual current increase at a slow rate of $0.001 \mathrm{~mA} \mathrm{~s}^{-1}$ from the minimum value of $0.08 \mathrm{~A}$ to $0.22 \mathrm{~A}$ observed at the 464th min of the electrolysis, at which the whole pellet is supposed to be composed of metallic cobalt. This observation can be explained based on the fact that the gradual reduction of cobalt oxide to cobalt by the electrochemically produced hydrogen increases the number of electroactive sites that are capable of acting as fresh conductive surfaces to discharge further hydrogen cations dissolved in the melt. This results in an increase in the current value, as shown in stage III of Fig. 6 . This stage can be dominated by the occurrence of reactions (6.1) and (6.2). An important and interesting point is that the products of these reactions are metallic cobalt, water and lithium oxide, and the latters can be instantly dissolved into the melt to re-generate hydrogen cations based on reactions (3) and (4.1), and oxygen anions based on reaction (4.2). Therefore, the occurrence of reactions (6.1), (6.2) and (4.1) at the stage III leads to the creation of a reduction loop, avoiding the escape of hydrogen from the melt, shown in the reaction (6). During the stage III, the hydrogen content of the melt is maintained at an approximately constant value, but the rates of reactions (6) and (4) gradually increase with increasing amounts of reduced metallic cobalt.

At the end of stage III, the pellet is mainly cobalt, and therefore the only dominant reaction should be the reactions (5.1) and (6) leading to the escape of hydrogen from the system and causing a shortage of hydrogen cations in the system, and consequently, 
a sharp drop in the current value. Also, the gradual passivation of the cobalt surface can contribute to the current drop observed, indicated as the stage IV. This stage could be an indication of the completion of the reduction reaction. At the end of stage III, a yield of $1.2 \mathrm{~g}$ metallic cobalt could be obtained, consuming around 4962 coulomb electric charge, calculated based on the current-time curve shown in Fig. 6 . The power consumption during the electrochemical process could, therefore, be estimated to be $1150 \mathrm{~kW} \mathrm{~h}$ per ton of the cobalt product.

3.4.2. Voltage-time variations. The voltage contributions between the anode and cathode during the polarisation under the cell voltage of $1 \mathrm{~V}$ are presented in Fig. 6 . In this figure, the black and red curves correspond to the electromotive force between the Mo-QRE immersed in the melt and either the cathode assembly (black line) or the graphite anode (red line) recorded throughout the electrolysis process. It can be clearly seen that the cathodic and anodic potentials vary with the electrolysis time. First of all, both curves follow the same pattern, due to the fact that the cell voltage, the sum of cathodic and anodic voltages, is constant at $1 \mathrm{~V}$. Therefore, any change in the value of one potential has to be compensated by the same value for the other voltage. Furthermore, as in the case of the $I-t$ graph (Fig. 6), the $V-t$ curves also exhibit four distinct stages. Based on the information extracted from these curves, the electrolysis starts with cathodic and anodic polarisation of around $-0.35 \mathrm{~V}$ and $0.65 \mathrm{~V}$, respectively, contributing to the high capacitive current observed (this section cannot be clearly observed in Fig. 6). Then, the values of cathodic and anodic voltages rapidly change to around $-0.25 \mathrm{~V}$ and $0.75 \mathrm{~V}$, respectively. These values correspond to the stage I in Fig. 6, during which the interaction at the cathode side is mainly characterised by the high yield generation of hydrogen (reaction (5.1)) on the fresh Ni wire surfaces.

The reduction in the value of the cathodic voltage indicates the low voltage required for the reduction of hydrogen cations on the fresh Ni wires. Then, after about $30 \mathrm{~min}$, a continuous increase in the cathodic potential (and the corresponding reduction of the anodic voltage) is observed, corresponding to the stage II of the $I-t$ curve. This stage is associated with the gradual passivation of the Ni wire surfaces, increasing the cathodic impedance, and consequently, the increase of the cathodic voltage and the resulting current drop. During the stages I and II, the hydrogen produced on the cathode can also reduce the surface of the cobalt oxide pellet into metallic cobalt, as observed in Fig. 5c. This phenomenon leads to a gradual recovery of current and the initiation of the stage III in the $I-t$ curve. In this stage, the combination of reactions (6.1), (6.2) and (4.1) will maintain the concentration of hydrogen cations adjacent to the cathode, and therefore an efficient reduction of the oxide phase occurs. Then, at the end of the process, the cathodic voltage sharply increases to values around $-0.5 \mathrm{~V}$ due to the passivation of the metallic cobalt cathode and the shortage of hydrogen cations available adjacent to the cathode. The passivation is mainly due to the formation of hydrogen gas on the cathode with no subsequent metal reduction. Since the experiment was conducted at a low cell voltage of $1 \mathrm{~V}$, the increase in the impedance of the cathode results in a sharp current decay, as observed in the $I-t$ curve. The mechanism explained above is responsible for the electrochemical production of hydrogen and the subsequent chemical reduction of cobalt oxide by the newly generated hydrogen through different stages, which can be verified using the characterisation results including the XRD and SEM data analysis.

\subsection{Remarks}

Here, we reported the electro-reduction of $\mathrm{Co}_{3} \mathrm{O}_{4}$ to Co under the influence of hydrogen produced in a molten salt environment. As discussed in the previous section, the mechanism involved in this process is based on the reduction of hydrogen cations available in the molten salt on metal oxide cathodes to form hydrogen (reaction (5.1)), which subsequently leads to the formation of metal and water, according to reactions (6.1) and (6.2). The water formed based on these reactions can instantly be dissolved in the molten salt to reform hydrogen cations. Therefore, theoretically, a small amount of water in molten salts should be sufficient to reduce a large amount of metal oxides immersed in the melt at a low cell potential which is just high enough to decompose water at high temperatures $(<1 \mathrm{~V})$. This mechanism, which is highlighted in Fig. 7, can be applied for a variety of metal oxides.

Apart from this, the predominantly fcc structure and highly faceted character of Co crystals formed in this study are remarkable. It should be noticed that below $420{ }^{\circ} \mathrm{C}$, cobalt displays a stable hcp crystal structure. At higher temperatures up to the melting point of $1495{ }^{\circ} \mathrm{C}$, the stable form of Co is fcc. Table S1 (ESI $\dagger$ ) shows the position and intensity of the reflection peaks observed in the XRD pattern of the electrolytic Co

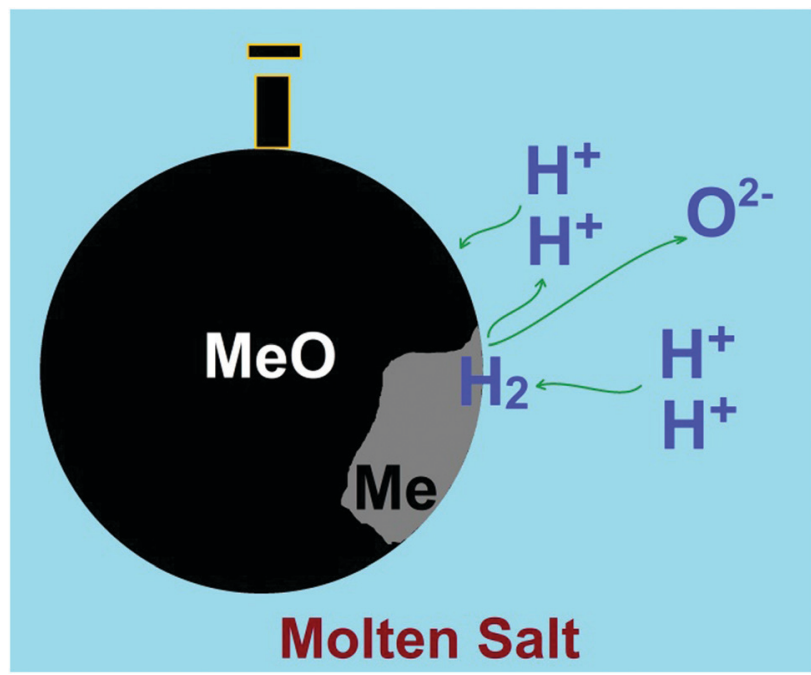

Fig. 7 Hydrogen cations present in molten salts can be reduced on cathodically polarised metal oxides to form water and the corresponding metal. The dissolution of produced water in the molten salt leads to the regeneration of hydrogen cations to continue the reduction process. 
produced after $8 \mathrm{~h}$ of electrolysis (Fig. 4e). By taking into account the intensity of diffraction peaks using the Rietveld method combined with the least squares method to adjust the structure and peak shape factors, the amounts of fcc and hep phases in the Co product can be estimated to be 84.12 and $15.88 \%$, respectively. This provides evidence that the fcc phase content is considerably high in our Co product at room temperature. The fraction of the fcc-Co phase in our work is compatible with other methods used to stabilise this phase. For example, Xie et al. ${ }^{33}$ ball-milled single phase hcp-Co powder with $1 \mathrm{wt} \% \mathrm{Y}_{2} \mathrm{O}_{3}$ and consolidated the powder via spark plasma sintering at $1000{ }^{\circ} \mathrm{C}$, leading to the fabrication of a Co material with around $76 \mathrm{wt} \%$ fcc-Co.

To investigate the reason for the stabilisation of the fcc-Co in our case, the electrolytic Co produced after $8 \mathrm{~h}$ of electrolysis was further analysed to determine its carbon, oxygen and hydrogen contents. For this, the sample was washed with distilled water 6 times, kept at $-20{ }^{\circ} \mathrm{C}$ for $12 \mathrm{~h}$ and then freeze-dried at $-50{ }^{\circ} \mathrm{C}$ under vacuum for $12 \mathrm{~h}$. The pellet was then crushed into pieces and ground. The obtained powder was analysed using a CHNO analyzer, from which the $\mathrm{O}, \mathrm{H}$ and $\mathrm{C}$ concentrations of the product were measured to be $0.112,0.113$ and $0.008 \mathrm{wt} \%$, respectively, confirming the desirable reduction of the cobalt oxide to cobalt powder. Moreover, according to this result, the carbon content of the Co product is very low, but the hydrogen content is considerably high. The presence of hydrogen in cobalt crystals can be explained based on the electrolytic production of hydrogen in molten salt, described in the section 3.4. The electrolytic hydrogen can diffuse into the Co powder in the molten salt environment. The hydrogen doping can, therefore, be responsible for the stabilisation of the fcc-Co at room temperature. It should be mentioned that the solubility of hydrogen in Co has scarcely been investigated in the literature. ${ }^{52,53}$ The current work provides an opportunity to investigate this phenomenon in molten salt environments in future works. A possible mechanism involved in the formation of faceted Co crystals can be based on the formation of H-doped Co crystallites through the hydrogen reduction of cobalt oxides and the subsequent growth of these crystallites into micrometer-sized faceted microcrystals, influenced by the fast diffusion rates of further reduced Co atoms, under the influence of the molten salt environment. The possible crystal shape determining parameters are also worth investigation.

What's more, the SEM micrograph of Fig. 5h clearly shows that H-doped Co displays a faceted crystalline morphology. The faceted crystalline nature of the Co product is interesting, considering that Co is usually produced by different methods in the form of polycrystalline particles with no faceted morphology. ${ }^{11,18,54}$

The formation of faceted metallic crystals has rather rarely been reported in the literature. For instance, faceted cobalt crystals were deposited using $20 \mathrm{~h}$ of electrolysis of a room temperature electrolyte containing $\mathrm{CoCl}_{2} \cdot 6 \mathrm{H}_{2} \mathrm{O}$ and $\mathrm{NaCl}$ at the $\mathrm{pH}$ of 3 using a copper cathode and a Co anode. ${ }^{55}$ Also, rice ear-like cobalt microcrystals were synthesised through the treatment of $\mathrm{CoCl}_{2} \cdot 6 \mathrm{H}_{2} \mathrm{O}$ with $\mathrm{N}_{2} \mathrm{H}_{4} \cdot \mathrm{H}_{2} \mathrm{O}, \mathrm{NaOH}$ and citric acid. ${ }^{56}$ As another example, hcp-Co crystals with sizes of around $10 \mathrm{~nm}$ were produced through the hydrothermal treatment of $\mathrm{Co}(\mathrm{AC})_{2} \cdot 4 \mathrm{H}_{2} \mathrm{O}$ and $\mathrm{NaF}$ at $180-200{ }^{\circ} \mathrm{C}$ for $48-60 \mathrm{~h}^{57}$

The molten salt method presented here is capable of producing well-faceted micrometer-sized fcc-dominated crystalline Co by using a clean and scalable method, without the requirement of using expensive and/or environmentally unsound chemicals. On one hand, the fcc-Co exhibits an enhanced level of toughness, making it attractive for applications such as high-performance cemented carbides. ${ }^{31-33}$ On the other hand, developing facile methods for the fabrication of faceted metallic crystals is interesting for both practical applications and basic research. ${ }^{58,59}$ For example, hcp-metallic cobalt microcrystals produced by solvothermal/hydrothermal methods using chemicals such as $\mathrm{CoCl}_{2} \cdot 6 \mathrm{H}_{2} \mathrm{O}$, ethylene glycol $\left(\mathrm{C}_{2} \mathrm{H}_{6} \mathrm{O}_{2}\right)$, and ethylene diamine $\left(\mathrm{C}_{2} \mathrm{H}_{8} \mathrm{~N}_{2}\right),{ }^{60}$ or $\mathrm{CoSO}_{4} \cdot 7 \mathrm{H}_{2} \mathrm{O}$, $\mathrm{NaNO}_{3}$, hydrazine hydrate $\left(\mathrm{N}_{2} \mathrm{H}_{4}\right)$ and $\mathrm{NaOH},{ }^{61}$ show remarkably enhanced magnetic properties due to their highly crystalline structure. Moreover, it is known that Co is an effective catalyst, for which the catalytic reactivity is facet-dependent and can be highly promoted in faceted crystals. ${ }^{62,63}$ The physical and mechanical properties of Co crystals produced by the molten salt method are interesting to study in future works.

In comparison with solid state electro-deoxidation processes, our proposed process uses moisture to promote the reduction of cobalt oxide at a considerably lower temperature and cell potential. For instance, for the reduction of $\mathrm{Co}_{3} \mathrm{O}_{4}$ in molten $\mathrm{CaCl}_{2}$, a high temperature of $850{ }^{\circ} \mathrm{C}$ and a cell voltage of $2.5 \mathrm{~V}$ are required. Furthermore, a comprehensive dehydration procedure should be applied to remove moisture from the system. This procedure includes the heating of the salt at $200{ }^{\circ} \mathrm{C}$ for 5 days under vacuum and the pre-electrolysis of the salt at $850{ }^{\circ} \mathrm{C}$ at a constant voltage of $1.5 \mathrm{~V}$ for several hours. ${ }^{28}$ This energy consumption is not usually included when the energy usage of these methods is reported. In the method proposed here, the as-received $\mathrm{LiCl}$ is directly heated to the relatively moderate temperature of $680{ }^{\circ} \mathrm{C}$ with no further treatment. Moreover, the process works at a low cell voltage of $1 \mathrm{~V}$, which makes the technology scalable.

Zisxik et al. ${ }^{64}$ used $\mathrm{SO}_{2}, \mathrm{H}_{2} \mathrm{O}$ and $\mathrm{I}_{2}$ to produce hydrogen at temperatures above $800{ }^{\circ} \mathrm{C}$, using the energy produced by molten salt nuclear reactors. Similar sources of heat can be utilised to melt the salt and to maintain the molten salt temperature in our case. Considering the low voltage employed in the proposed technology $(1 \mathrm{~V})$, the electricity required can be produced using photovoltaic cells, ${ }^{65,66}$ offering a green methodology for the production of hydrogen and the reduction of cobalt oxides. Table S2 (ESI $\dagger$ ) compares a selection of different methods used for the reduction of cobalt oxides to metallic cobalt, based on the data available in the literature. Fig. S4 (ESI $\dagger$ ) summarises the phase transitions from the initial CoO particles into well-faceted cobalt microcrystals occurring during the process described in this article. As mentioned, $\mathrm{H}$-doped Co with a dominant fcc-structure is interesting for various practical applications such as high performance WC-C composites, as well as basic research. 


\section{Conclusions}

The reduction of cobalt oxides to metallic cobalt was achieved via the cathodic polarisation of oxides in molten $\mathrm{LiCl}$ at $680{ }^{\circ} \mathrm{C}$ under a humid $\mathrm{Ar}$ atmosphere at a low cell potential of only $1 \mathrm{~V}$. The mechanism involved in this reduction process was explained based on the formation of $\mathrm{H}^{+}$from water in the atmosphere and the discharge of hydrogen cations on the cathode to form hydrogen gas. The formed hydrogen gas has the kinetic and thermodynamic capability at the molten salt temperature to reduce the cobalt oxide phase into metallic cobalt. The Co product was found to have a faceted morphology with a stable fcc-dominated crystalline phase that is formed through the doping of Co with hydrogen. Here, water is the source of hydrogen in the electrolytic reduction process. After completion of the hydrogen reduction, water can be re-generated in the melt. This approach can be considered as a sustainable way for the preparation of Co with no greenhouse gas emission. The energy consumption in this approach is estimated to be $1150 \mathrm{~kW} \mathrm{~h}$ per ton of the reduced cobalt. These results make the method attractive for large scale operations. Considering the low voltage employed in the proposed technology $(1 \mathrm{~V})$, the electricity required can be produced using photovoltaic cells, offering a green methodology for the production of hydrogen and the reduction of cobalt oxides.

\section{Conflicts of interest}

There are no conflicts to declare.

\section{Acknowledgements}

This work was financially supported by the National Natural Science Foundation of China (51750110513) and the Fundamental Research Funds for the Central Universities (N2025001). D. Qiao and K. Xie conducted the experiments and characterisations; A. R. Kamali designed and supervised the research, and wrote the article.

\section{Notes and references}

1 Z. Hu, D. Ma, H. Qu, H. Zhang, C. Luo and H. Wang, The role of cobalt addition in magnetic and mechanical properties of high intrinsic coercivity Nd-Fe-B magnets, J. Alloys Compd., 2018, 763, 273-277.

2 A. Karimzadeh, M. Aliofkhazraei and F. C. Walsh, A review of electrodeposited Ni-Co alloy and composite coatings: Microstructure, properties and applications, Surf. Coat. Technol., 2019, 372, 463-498.

3 C. Gao, H. Wang, S. Li, B. Liu, J. Yang, J. Gao, Z. Peng, Z. Zhang and Z. Liu, Enhanced cobalt-based catalysts through alloying ruthenium to cobalt lattice matrix as an efficient catalyst for overall water splitting, Electrochim. Acta, 2019, 327, 134958.

4 B. Liang, Y. Wang, X. Liu, T. Tan, L. Zhang and W. Wang, Nickel-cobalt alloy doping phosphorus as advanced electrocatalyst for hydrazine oxidation, J. Alloys Compd., 2019, 807, 151648.

5 L. X. Tan, Y. I. M. Zhong and C. L. Luo, Preparation of spherical cobalt powder and its application in ultra-fine cemented carbides, Chin. J. of Nonferrous Met., 2008, 18, 209-214.

6 P. Kumar Katiyar, P. Kumar Singh, R. Singh and A. L. Kumar, Modes of failure of cemented tungsten carbide tool bits (WC/Co): A study of wear parts, Int. J. Refract. Met. Hard Mater., 2016, 54, 27-38.

7 S. Qi, D. Wu, Y. Dong, J. Liao, C. W. Foster, C. O'Dwyer, Y. Feng, C. Liu and J. Ma, Cobalt-based electrode materials for sodium-ion batteries, Chem. Eng. J., 2019, 370, 185-207.

8 N. Nitta, F. Wu, J. T. Lee and G. Yushin, Li-ion battery materials: present and future, Mater. Today, 2015, 18, 252-264.

9 Y. Srivastava and S. Srivastava, Preparation and properties of Cobalt-based soft magnetic material prepared by novel powder metallurgy, J. Magn. Magn. Mater., 2017, 423, 267-274.

10 J. A. Betancourt-Cantera, S. D. Jesús, A. M. Bolarín-Miró, G. Torres-Villaseñor and L. G. Betancourt-Cantera, Magnetic properties and crystal structure of elemental cobalt powder modified by high-energy ball milling, J. Mater. Res. Technol., 2019, 8, 4995-5003.

11 S. Liu, K. Xu and M. Wang, Preparation of Co powders for cemented carbides in China, Int. J. Refract. Met. Hard Mater., 2006, 24, 405-412.

12 J.-E. Bidaux, R. Schaller and W. Benoit, Study of the H.C.P.-F.C.C. phase transition in cobalt by acoustic measurements, Acta Metall., 1989, 37, 803-811.

13 J. J. Roa, E. Jiménez-Piqué, J. M. Tarragó, M. Zivcec, C. Broeckmann and L. Llanes, Berkovich nanoindentation and deformation mechanisms in a hardmetal binder-like cobalt alloy, Mater. Sci. Eng., A, 2015, 621, 128-132.

14 K. P. Mingard, B. Roebuck, J. Marshall and G. Sweetman, Some aspects of the structure of cobalt and nickel binder phases in hardmetals, Acta Mater., 2011, 59, 2277-2290.

15 S. I. Cha, S. H. Hong, G. H. Ha and B. K. Kim, Mechanical properties of WC-10Co cemented carbides sintered from nanocrystalline spray conversion processed powders, Int. J. Refract. Met. Hard Mater., 2001, 19, 397-403.

16 W. S. W. Harun, M. S. I. N. Kamariah, N. Muhamad, S. A. C. Ghani, F. Ahmad and Z. Mohamed, A review of powder additive manufacturing processes for metallic biomaterials, Powder Technol., 2018, 327, 128-151.

17 J. Deng, S. Li, Y. Zhou, L. Liang, B. Zhao, X. Zhang and R. Zhang, Enhancing the microwave absorption properties of amorphous $\mathrm{CoO}$ nanosheet-coated Co (hexagonal and cubic phases) through interfacial polarizations, J. Colloid Interface Sci., 2018, 509, 406-413.

18 S. Cetinkaya and S. Eroglu, Synthesis of Cobalt Powder by Reduction of Cobalt Oxide with Ethanol, JOM, 2018, 70, 2237-2242.

19 H. Y. Lin and Y. W. Chen, The mechanism of reduction of cobalt by hydrogen, Mater. Chem. Phys., 2004, 85, 171-175. 
20 A. M. Abdalla., S. Hossain, O. B. Nisfindy, A. T. Azad, M. Dawood and A. K. Azad, Hydrogen production, storage, transportation and key challenges with applications: A review, Energy Convers. Manage., 2018, 165, 602-627.

21 J. Kurtz, S. Sprik and T. H. Bradley, Review of transportation hydrogen infrastructure performance and reliability, Int. J. Hydrogen Energy, 2019, 44, 12010-12023.

22 J. Mustroph, S. Lebek, L. S. Maier and S. Neef, Mechanisms of cardiac ethanol toxicity and novel treatment options, Pharmacol. Ther., 2019, 197, 1-10.

23 P. Patnai, S. K. Padhy, B. C. Tripathy, I. N. Bhattacharya and R. K. Paramguru, Electrodeposition of cobalt from aqueous sulphate solutions in the presence of tetra ethyl ammonium bromide, Trans. Nonferrous Met. Soc. China, 2015, 25, 2047-2053.

24 M. Li, B. Gao, Z. Shi, X. Hu, S. Wang, L. Li, Z. Wang and J. Yu, Electrodeposition of cobalt from urea-acetamide-LiBr melt, J. Solid State Electrochem., 2016, 20, 247-254.

25 R. Fukui, Y. Katayama and T. Miura, The effect of organic additives in electrodeposition of Co from an amide-type ionic liquid, Electrochim. Acta, 2011, 56, 1190-1196.

26 X. Cheng, D. Tang, D. Tang, H. Zhu and D. Wang, Cobalt Powder Production by Electro-Reduction of $\mathrm{Co}_{3} \mathrm{O}_{4}$ Granules in Molten Carbonates Using an Inert Anode, J. Electrochem. Soc., 2015, 162, 68-72.

27 K. Zheng, X. Cheng, Y. Dou, H. Zhu and D. Wang, Electrolytic Production of Nickel-Cobalt Magnetic Alloys from Solid Oxides in Molten Carbonates, J. Electrochem. Soc., 2017, 164, 422-427.

28 D. J. S. Hyslop, A. M. Abdelkader, A. Cox and D. J. Fray, Electrochemical synthesis of abiomedically important CoCr alloy, Acta Mater., 2010, 58, 3124-3130.

29 L. Prakash, in Comprehensive Hard Materials, ed. D. Mari, L. Llanes and V. K. Sarin, Elsevier, Oxford, UK, 2014, vol. 1, pp. 29-90.

30 P. K. Katiyar, P. K. Singh, R. Singh and A. Kumar, Modes of failure of cemented tungsten carbide tool bits (WC/Co): A study of wear parts, Int. J. Refract. Met. Hard Mater., 2016, 54, 27-38.

31 J. M. Marshall and M. Giraudel, The role of tungsten in the Co binder: effects on WC grain size and hcp-fcc Co in the binder phase, Int. J. Refract. Met. Hard Mater., 2015, 49, 57-66.

32 S. I. Cha, S. H. Hong, G. H. Ha and B. K. Kim, Mechanical properties of WC-10Co cemented carbides sintered sintered from nanocrystalline spray conversion processed powders, Int. J. Refract. Met. Hard Mater., 2001, 19, 397-403.

$33 \mathrm{Z}$. Xie, S. Ni and M. Song, Effect of $\mathrm{Y}_{2} \mathrm{O}_{3}$ doping on FCC to HCP phase transformation in cobalt produced by ball milling and spark plasma sintering, Powder Technol., 2018, 324, 1-4.

34 J. A. Betancourt-Cantera, F. Sánchez-De Jesús, A. M. BolarínMiró, G. Torres-Villasenor and L. G. Betancourt-Cantera, Magnetic properties and crystal structure of elemental cobalt powder modified by high-energy ball milling, $H$. Mater. Res. Technol., 2019, 201, 4995-5003.
35 J. Y. Huang, Y. K. Wu and H. Q. Ye, Allotropic transformation of cobalt induced by ball milling, Acta Mater., 1996, 44, 1201-1209.

36 K. Jia, T. E. Fischer and B. Gallois, Microstructure, hardness and toughness of nanostructured and conventional WC-Co composites, Nanostruct. Mater., 1998, 10, 875-891.

37 J. M. Marshall and M. Giraudel, The role of tungsten in the Co binder: Effects on WC grain size and hcp-fcc Co in the binder phase, Int. J. Refract. Met. Hard Mater., 2015, 49, $57-66$.

38 K. Jia, T. E. Fischer and B. Gallois, Microstructure, hardness and toughness of nanostructured and conventional WC-Co composites, Nanostruct. Mater., 1998, 10, 875-891.

39 M. Ogura, T. Fukushima, R. Zeller and P. H. Dederichs, Structure of the high-entropy alloy AlxCrFeCoNi: fcc versus bcc, J. Alloys Compd., 2017, 715, 454-459.

40 A. R. Kamali, D. J. Fray and C. Schwandt, Thermokinetic characteristics of lithium chloride, J. Therm. Anal. Calorim., 2011, 104, 619-626.

41 A. R. Kamali, Eco-friendly production of high quality low cost graphene and its application in lithium ion batteries, Green Chem., 2016, 18, 1952-1964.

42 A. R. Kamali, Scalable fabrication of highly conductive 3D graphene by electrochemical exfoliation of graphite in molten $\mathrm{NaCl}$ under $\mathrm{Ar} / \mathrm{H}_{2}$ atmosphere, J. Ind. Eng. Chem., 2017, 52, 18-27.

43 A. Rezaei and A. R. Kamali, Green production of carbon nanomaterials in molten salts, mechanisms and applications, Diamond Relat. Mater., 2018, 83, 146-161.

44 A. Rezaei, B. Kamali and A. R. Kamali, Correlation between morphological, structural and electrical properties of graphite and exfoliated graphene nanostructures, Measurement, 2020, 150, 107087.

45 A. R. Kamali, H. K. Kim, K. B. Kim, R. V. Kumar and D. J. Fray, Large scale green production of ultra-high capacity anode consisting of graphene encapsulated silicon nanoparticles, J. Mater. Chem. A, 2017, 5, 19126-19135.

46 A. R. Kamali, Nanocatalytic conversion of $\mathrm{CO}_{2}$ into nanodiamonds, Carbon, 2017, 123, 205-215.

47 K. Xie and A. R. Kamali, Electro-reduction of hematite using water as the redox mediator, Green Chem., 2019, 21, 198-204.

48 K. Xie and A. R. Kamali, Molten salt electrochemical production and in situ utilization of hydrogen for iron production, Int. J. Hydrogen Energy, 2019, 44, 24353-24359.

49 M. Zyłaa, G. Smołaa, A. Knapika, J. Ryszb, M. Sitarza and Z. Grzesika, The formation of the $\mathrm{Co}_{3} \mathrm{O}_{4}$ cobalt oxide within CoO substrate, Corros. Sci., 2016, 112, 536-541.

50 M. P. Hyman and J. M. Vohs, Reaction of ethanol on oxidized and metallic cobalt surfaces, Surf. Sci., 2011, 605, 383-389.

51 G. Barcaro and A. Fortunelli, 2D oxides on metal materials: concepts, status, and perspectives, Phys. Chem. Chem. Phys., 2019, 21, 11510-11536.

52 S. W. Staford and R. McLellan, The solubility of hydrogen in nickel and cobalt, Acta Metall., 1974, 33, 1463-1468. 
53 R. G. Blossey and R. D. Pehlke, Solubility of hydrogen in liquid Fe-Co-Ni alloys, Metall. Mater. Trans. B, 1971, 2, 3157-3161.

54 S. Wen, Y. Liu, X. Zhao, J. Cheng and H. Li, Facile synthesis of novel cobalt particles by reduction method and theirmicrowave absorption properties, Powder Technol., 2014, 264, 128-132.

55 Q. Song, Y. Zha, C. Wang, H. Xie, H. Yin and Z. Nin, Bubbleassisted densification of cobalt deposit during electrowinning in $\mathrm{CoCl}_{2}$ solution, Hydrometallurgy, 2019, 189, 105111.

56 Y. Li, J. Zha, Y. Zhu, D. Ma, Y. Zha, S. Hou, F. Yan and Z. Wang, Controlled synthesis of rice ear-like cobalt microcrystals at room temperature, Colloids Surf., A, 2010, 356, 156-161.

57 X. Wang, H. Fu, A. Peng, T. Zhai, Y. Ma, F. Yuan and J. Yao, One-pot solution synthesis of cubic cobalt nanoskeletons, Adv. Mater., 2009, 21, 1636-1640.

58 K. Y. Ng, A. Muley, Y. F. Chan, A. C. M. Ng, A. B. Djurišić and A. H. W. Ngan, Highly facetted metallic zinc nanocrystals fabricated by thermal evaporation, Mater. Lett., 2006, 60, 2423-2427.

59 W. Shou, B. K. Mahajan, B. Ludwig, X. Yu, J. Staggs, $\mathrm{X}$. Huang and H. Pan, Low-cost manufacturing of bioresorbable conductors by evaporation-condensation-mediated laser printing and sintering of $\mathrm{Zn}$ nanoparticles, Adv. Mater., 2017, 29, 1700172.
60 L. J. Zhao, L. F. Duan, Y. Q. Wang and Q. Jiang, Fabrication and Magnetic Properties of Cobalt Microcrystals, J. Phys. Chem. C, 2010, 114, 10691-10696.

61 R. H. Wang, J. S. Jiang and M. Hu, Metallic cobalt microcrystals with flowerlike architectures: Synthesis, growth mechanism and magnetic properties, Mater. Res. Bull., 2009, 44, 1468-1473.

62 M. Rahmati, M. S. Safdari, T. H. Fletcher, M. D. Argyle and C. H. Bartholomew, Chemical and Thermal Sintering of Supported Metals with Emphasis on Cobalt Catalysts During Fischer-Tropsch Synthesis, Chem. Rev., 2020, 120, 4455-4533.

63 J. Pala and T. Pal, Faceted metal and metal oxide nanoparticles: design, fabrication and catalysis, Nanoscale, 2015, 7, 14159-14190.

64 G. Özisxik, N. Demir, M. Übeyli and H. Yapici, Hydrogen production via water splitting process in a molten-salt fusion breeder, Int. J. Hydrogen Energy, 2010, 35, 7357-7368.

65 F. Lombeck, S. Müllers, H. Komber, S. M. Menke, A. J. Pearson, P. J. Conaghan, C. R. McNeill and R. H. Friend, M. Benzoyl, sidechains push the open-circuit voltage of PCDTBT/PCBM solar cells beyond 1 V, Org. Electron., 2017, 49, 142-151.

66 D. Zhu, X. Bao, D. Ouyang, J. Wang, X. Yuan, Q. Wang, D. Zhou, S. Wen and R. Yang, Single-junction fullerene solar cells with $10 \%$ efficiency and high open-circuit voltage approaching 1 V, Nano Energy, 2017, 40, 495-503. 